\title{
PENINGKATAN EMPOWERMENT (PEMBERDAYAAN) PEREMPUAN MELALUI KELAS HYPNOPRENATAL PADA IBU HAMIL
}

\author{
Suryaningsih \\ Program Studi D3 Kebidanan Bangkalan, Politeknik Kesehatan Kemenkes Surabaya, \\ yandrie.marza1405@gmail.com \\ Rodiyatun \\ Program Studi D3 Kebidanan Bangkalan, Politeknik Kesehatan Kemenkes Surabaya \\ Moh. Choirin \\ Program Studi D3 Kebidanan Bangkalan, Politeknik Kesehatan Kemenkes Surabaya \\ Kharisma Kusumaningtyas \\ Program Studi D3 Kebidanan Bangkalan, Politeknik Kesehatan Kemenkes Surabaya
}

\begin{abstract}
Abstrak
Rasa takut/ kecemasan akan mempengaruhi klien dalam menghadapi kehamilan dan persalinan yang akan berpengaruh terhadap kesakitan ibu. Belum ada bidan di wilayah kerja Puskesmas Socah Bangkalan yang memberikan pelayanan holistik. Hypnoprenatal merupakan pemrograman pikiran bawah sadar klien sebagai upaya persiapan persalinan menggunakan teknik hypnosis yang bertujuan untuk menjadikan proses persalinan menjadi aman, nyaman dan menyenangkan. Sasaran hypnoprenatal kelas sebanyak 21 ibu hamil trimester 2 dan 3 di wilayah kerja Puskesmas Socah. Kelas ini dilaksanakan sebanyak 5 kali dengan waktu tiap sesi hypnoprenatal selama 60 - 90 menit. Kegiatan yang dilakukan selama kelas hypnoprenatal meliputi Pemeriksaan Kehamilan, Pelaksanaan Hypnoprenatal, Pemasangan Anchor, Senam Hamil/ Yoga Prenatal, Pengatasan Keluhan. Secara keseluruhan ibu hamil trimester 2 dan 3 tidak terdapat kontraindikasi untuk dilakukan hypnoprenatal maupun yoga antenatal. Seluruh ibu hamil mengikuti kegiatan dengan kondisi yang santai, dan nyaman. Hasil rekapitulasi kuesioner pre test dan post test kelas hypnoprenatal didapatkan secara keseluruhan ibu dapat mengatasi kecemasan dan merasa lebih tenang dalam menjalani kehamilan, dan merasa lebih siap dalam menghadapi persalinan. Secara keseluruhan ibu hamil menyatakan telah mengulang anchor yang dipasang setiap waktu. Diharapkan semua bidan dapat memberikan asuhan antenatal secara holistic dengan menambahkan layanan hypnoprenatal agar ibu hamil dapat meningkatkan kemampuan untuk mengelola kondisi fisik dan psikisnya sendiri dalam menjalani kehamilan dan persalinan.
\end{abstract}

Kata Kunci: Hypno, prenatal, kelas

\section{Abstract}

Anxiety will affect the client in facing pregnancy and labor/childbirth which will affect the mother's pain. There is no midwife in the working area of Puskesmas Socah Bangkalan that provides holistic services. Hypnoprenatal is programming client's subconscious mind as an effort to prepare for labor using a hypnosis technique that aims to make the delivery process safe, comfortable and enjoyable. The hypnoprenatal class targets 21 pregnant women in trimester 2 and 3 in the working area of Puskesmas Socah. This class is held 5 times with each $60-90$ minute hypnoprenatal session. Activities carried out during the hypnoprenatal class include Pregnancy Examination, Hypnoprenatal Practice, Anchor (Anchoring), Pregnancy Exercise / Prenatal Yoga, and Complaint Overcoming. Overall, pregnant women in the second and third trimesters have no contraindications for hypnoprenatal act or antenatal yoga. All pregnant women participated in activities which was relaxed and comfortable. The results of the recapitulation of the pre and post hypnoprenatal questionnaires is that all mothers could overcome anxiety and feel more calm in living pregnancy, and feel better prepared for labor. Overall, pregnant women say they have repeated previous anchors. It is expected that all midwives can provide antenatal care holistically by adding hypnoprenatal services so that pregnant women can improve their ability to manage their own physical and psychological conditions in undergoing pregnancy and labor.

Keywords: Hypno, prenatal, class 


\section{PENDAHULUAN}

Kehamilan dan persalinan adalah kondisi yang alamiah bagi setiap perempuan, karena kehamilan merupakan kondisi yang sangat diharapkan bagi setiap pasangan. Namun demikian, banyak wanita yang merasa takut dan tidak nyaman dengan kehamilannya. Bahkan, kecemasan tersebut semakin berkembang mendekati proses persalinan. Pada akhirnya ibu akan mengalami rasa nyeri yang luar biasa pada proses persalinan yang justru dapat menghambat kelancaran proses persalinan.

Tidak jarang persalinan justru menjadi kondisi yang dapat membahayakan bagi keselamatan ibu dan janin. Oleh karena itu, setiap tenaga kesehatan harus mampu mengoptimalkan pemeriksaan kehamilan (antenatal care) untuk meningkatkan rasa nyaman dan rasa percaya ibu terhadap tenaga kesehatan yang akan menolong persalinan. Penggunaan hipnotherapi dapat menurunkan kecemasan pada ibu, karena selama antenatal care ibu bisa mendapatkan sugesti yang merubah mindset terhadap rasa sakit yang muncul pada masa persalinan. Terapi hipnosis yang dilakukan pada ibu sebaiknya bukan hanya sekali, tapi berulang selama antenatal care (standar minimal anc adalah $4 \mathrm{x}$ ), sehingga pikiran bawah sadar ibu dapat memahami arti nyeri yang sesungguhnya dalam proses persalinan. Hasil penelitian menunjukkan ibu hamil yang mendapatkan self hypnosis pada saat antenatal mengalami penurunan tingkat kecemasan dan nyeri (Anantasari, 2012). Penelitian lain menunjukkan hypnosis dapat meningkatkan pengalaman melahirkan yang nyaman, menurunkan komplikasi selama kehamilan dan persalinan. (Cyna, 2006)

Penggunaan bahasa hipnosis dalam antenatal dan proses persalinan pun dapat mengurangi rasa nyeri dan kecemasan ibu. Kadang sebagai tenaga kesehatan, masih menggunakan bahasa yang kurang tepat yang justru meningkatkan kecemasan dan rasa nyeri ibu. Hypnoprenatal merupakan pemrograman pikiran bawah sadar klien sebagai upaya persiapan persalinan menggunakan teknik hypnosis yang bertujuan untuk menjadikan proses persalinan menjadi aman, nyaman dan menyenangkan. Oleh karena itu, penguasaan hipnoterapi oleh tenaga kesehatan sangat membantu menurunkan angka kesakitan ibu.

Dari studi pendahuluan di Puskesmas Socah Kabupaten Bangkalan didapatkan data bahwa $100 \%$ ibu hamil belum mengikuti kelas hypnoprenatal sebagai upaya untuk meningkatkan pemberdayaan perempuan yang berarti ibu akan mampu mengelola kondisi fisiknya dan psikisnya sendiri dalam menjalani kehamilan, persalinan, paska melahirkan dan menyusui 
sehingga dirasa perlu untuk memberikan bantuan tenaga dalam melaksanakan kelas hypnoprental di Puskesmas Socah Kecamatan Socah Kabupaten Bangkalan.

Rasa takut/ kecemasan akan mempengaruhi klien dalam menghadapi kehamilan dan persalinan yang akan berpengaruh terhadap kesakitan ibu. Belum ada bidan yang memberikan pelayanan holistik dengan meningkatkan pemberdayaan perempuan agar mampu meningkatkan kemampuan dirinya untuk mengelola kondisi fisik dan psikisnya sendiri dalam menjalani kehamilan dan persalinan.

Berdasarkan permasalahan diatas Dosen di Program Studi Kebidanan Bangkalan yang telah tersertifikasi IBH sebagai hypnotherapist, merasa terpanggil untuk mengaplikasikan dan mengabdikan ilmunya kepada masyarakat. Tujuan kegiatan ini adalah terselenggaranya kegiatan kelas hypnoprenatal dapat meningkatkan pemberdayaan perempuan dalam menghadapi kehamilan dengan tujuan khusus terselenggaranya kegiatan kelas hypnoprenatal pada semua ibu hamil trimester 2 dan 3 di Puskesmas Socah Kecamatan Socah Bangkalan. Dan tercapainya kemandirian perempuan/ ibu hamil untuk mengelola kondisi fisik dan psikisnya sendiri dalam menjalani kehamilan dan persalinan. Pengabdian kepada masyarakat ini bermanfaat bagi ibu hamil untuk meningkatkan kemampuan mengelola kondisi fisik dan psikisnya sendiri dalam menjalani kehamilan dan persalinan serta membantu pencapaian kegiatan program pada Dinas Kesehatan Kabupaten Bangkalan utamanya pada program pemeriksaan antenatal care.

Hypnoprenatal berasal dari kata hypnosisi dan prenatal yang berarti segala sesuatu yang terkait dengan pengetahuan tentang pemodelan kesadaran (conscious Mind and subconscious mind), fenomena trance, keluaran sugesti dan berbagai teknik dasar untuk membawa seseorang ke kondisi Trance. Sedangkan prenatal memiliki makna sebelum kelahiran sebagai upaya persiapan untuk melahirkan. Hypnoprenatal berarti pemrograman pikiran bawah sadar klien sebagai upaya persiapan kelahiran menggunakan teknik hypnosis yang bertujuan untuk menjadikan proses persalinan menjadi aman, nyaman, dan menyenangkan. Seringkali ibu merasakan kekhawatiran yang berlebihan atas kehamilan yang dijalaninya, proses persalinan yang menyakitkan, kesedihan pasca melahirkan dan menyusui.

\section{GAMBARAN UMUM MASYARAKAT SASARAN}

Sasaran kelas hypnoprenatal adalah Ibu hamil trimester 2 dan 3 di Puskesmas Socah Kecamatan Socah pada bulan Mei - Juli 2017 yang secara keseluruhan belum pernah mendapatkan layanan hypnoprenatal. 


\section{METODE}

Kelas hypnoprenatal dilaksanakan setelah memasuki kehamilan trimester 2 dan 3 yang bertujuan untuk meningkatkan kemampuan ibu dalam mengelola kondisi fisik dan psikisnya dalam menjalani kehamilan, persalinan, pasca melahirkan dan menyusui. Kelas ini dilaksanakan sebanyak 5 kali dengan waktu tiap sesi hypnoprenatal selama $60-90$ menit. Kegiatan yang dilakukan selama kelas hypnoprenatal meliputi Pemeriksaan Kehamilan, Pelaksanaan Hypnoprenatal, Pemasangan Anchor, Senam Hamil/ Yoga Prenatal, Pengatasan Keluhan.

Sasaran kelas hypnoprenatal adalah 21 orang ibu hamil trimester 2 dan 3 yang berada di wilayah kerja Puskesmas Socah Kabupaten Bangkalan. Berdasarkan hasil pemeriksaan awal seluruh ibu hamil tidak memiliki kontraindikasi untuk dilakukan hypnoprenatal sehingga secara keseluruhan mengikuti kelas hypnoprenatal.

Metode yang dilaksanakan diawali dengan membentuk kelas Hypnoprenatal dan melakukan pemeriksaan kehamilan sesuai standar untuk mendeteksi adanya kontraindikasi pelayanan hypnoprenatal dilanjutkan dengan melakukan pelayanan kelas hypnoprenatal minimal 5 kali pertemuan dengan waktu 60 - 90 menit untuk mendapatkan hasil yang maksimal yang meliputi pemberian informed concent, penjelasan tentang hypnosis, pre induction talk (anamnesis), medical hystory, Tes sugestibilitas, relaksasi/ hypnosis, pemasangan anchor, senam hamil/ Yoga prenatal, afirmasi, atasi keluhan klien jika ada dan Evaluasi/ buat kesepakatan jadwal selanjutnya.

\section{HASIL DAN PEMBAHASAN}

Kelas hypnoprenatal telah terbentuk dengan sasaran 21 orang ibu hamil trimester 2 dan 3. Setelah dilaksanakan pemeriksaan kehamilan tidak didapatkan kontraindikasi untuk mendapatkan pelayanan hypnoprenatal. Kelas hypnoprenatal telah dilaksanakan sebanyak 5 kali pertemuan yaitu pada tanggal 3 Mei 2017, 15 Mei 2017, 24 Mei 2017, 5 Juni 2017 dan 14 Juni 2017.

\section{Pertemuan pertama}

Kegiatan dilakukan dalam 3 sesi karena tempat di Polindes Socah yang tidak memungkinkan untuk menampung seluruh ibu hamil untuk satu kali sesi kelas hypnoprenatal. Masing masing sesi terdiri dari 7 ibu hamil trimester 2 dan 3 .

Pada pertemuan pertama ini diawali dengan pengisian kuesioner tentang kecemasan dalam menjalani kehamilan dilanjutkan dengan penjelasan tentang kelas hypnoprenatal, informed concent, pemeriksaan kehamilan dan pengatasan keluhan, hypnoprenatal dan pemasangan anchor, serta yoga prenatal. 
Hasil pengisian kuesioner menunjukkan $68 \%$ ibu hamil mengalami kecemasan dalam menjalani proses kehamilan, serta menjelang persalinan. Sebagian besar ibu belum melakukan komunikasi secara kontinue dengan bayi untuk membangun bonding attacment antara ibu dan bayi.

Pemeriksaan kehamilan dilakukan untuk mendeteksi apakah dalam kehamilan ini terdapat kontraindikasi untuk melakukan hypnoprenatal maupun yoga antenatal. Dari keseluruhan ibu hamil didapatkan tidak terdapat kontraindikasi .

Pemasangan anchor dengan membimbing ibu berada dalam suatu tempat yang disukai dan memasuki kondisi penuh kebahagiaan dan keceriaan. Anchor dipasang dengan meletakkan tangan kanan ibu didada sambil melakukan afirmasi bahwa mulai saat ini dan seterusnya setiap kali ibu meletakkan tangan kanan didada dan menarik nafas dalam, maka secara otomatis ibu akan berada ditempat dan kondisi bahagia yang dialami saat ini. Ibu diminta untuk mengulangi pemasangan anchor setiap hari pada setiap menjelang tidur selama 21 hari. Hal ini dapat bermanfaat untuk mengurangi kecemasan, serta rasa nyeri pada saat proses persalinan.

Yoga prenatal dilakukan untuk membuat ibu hamil mampu mempersiapkan fisik dan psikologis selama proses kehamilan, persalinan dan nifas. Pada pertemuan pertama ini dipilih yoga dengan durasi yang pendek yaitu selama 15 menit yang terdiri dari adhomukha svanasana, tadasana, virksasana, trikonasana, virabhadrasana dan savasana diakhiri dengan rileksasi.

\section{Pertemuan kedua}

Kegiatan dilakukan dalam 3 sesi karena tempat di Polindes Socah yang tidak memungkinkan untuk menampung seluruh ibu hamil untuk kelas hypnoprenatal. Masing masing sesi terdiri dari 7 ibu hamil trimester 2 dan 3.

Pada pertemuan kedua ini diawali dengan penjelasan kembali tentang kelas hypnoprenatal, informed concent pemeriksaan kehamilan dan pengatasan keluhan, hypnoprenatal dan pemasangan anchor, serta yoga prenatal.

Pemeriksaan kehamilan dilakukan untuk mendeteksi apakah dalam kehamilan ini terdapat kontraindikasi untuk melakukan hypnoprenatal maupun yoga antenatal. Dari keseluruhan ibu hamil didapatkan tidak terdapat kontraindikasi . Seluruh ibu hamil mengikuti proses hypnoprenatal dan yoga prenatal. Pemasangan anchor dengan membimbing ibu berada dalam suatu tempat yang disukai dan memasuki kondisi penuh kebahagiaan dan keceriaan. Anchor dipasang dengan meletakkan tangan kanan ibu didada sambil melakukan afirmasi bahwa mulai saat ini dan seterusnya setiap kali ibu meletakkan tangan kanan didada 
dan menarik nafas dalam, maka secara otomatis ibu akan berada ditempat dan kondisi bahagia yang dialami saat ini. Ibu diminta untuk mengulangi pemasangan anchor setiap hari pada setiap menjelang tidur selama 21 hari. Hal ini dapat bermanfaat untuk mengurangi kecemasan, serta rasa nyeri pada saat proses persalinan. Secara keseluruhan ibu hamil telah melakukan pengulangan pemasangan anchor setiap menjelang tidur dan kadang kadang diwaktu yang lain dan sudah melakukan komunikasi dengan bayi secara kontinue. Sebagian merasa lebih tenang dan lebih enjoy dalam menjalani kehamilan.

Yoga prenatal dilakukan untuk membuat ibu hamil mampu mempersiapkan fisik dan psikologis selama proses kehamilan, persalinan dan nifas. Pada pertemuan kedua ini dipilih yoga dengan durasi yang lebih lama yaitu selama 30 menit yang terdiri dari unsolutation A, adhomukha svanasana, tadasana, trikonasana, virabhadrasana II, Utthita parsvakonasana, Ardha chandrasana, Prenatal Chaturangga, virksasana, diakhiri dengan rileksasi.

\section{Pertemuan ketiga}

Kegiatan dilakukan dalam 3 sesi karena tempat di Polindes Socah yang tidak memungkinkan untuk menampung seluruh ibu hamil untuk kelas hypnoprenatal. Masing masing sesi terdiri dari 6 - 7 ibu hamil trimester 2 dan 3.
Pada pertemuan ketiga ini diawali dengan penjelasan kembali tentang kelas hypnoprenatal, informed concent pemeriksaan kehamilan dan pengatasan keluhan, hypnoprenatal dan pemasangan anchor, serta yoga prenatal.

Pemeriksaan kehamilan dilakukan untuk mendeteksi apakah dalam kehamilan ini terdapat kontraindikasi untuk melakukan hypnoprenatal maupun yoga antenatal. Dari keseluruhan ibu hamil didapatkan tidak terdapat kontraindikasi. Seluruh ibu hamil mengikuti proses hypnoprenatal dan yoga prenatal.

Pemasangan anchor dengan membimbing ibu berada dalam suatu tempat yang disukai dan memasuki kondisi penuh kebahagiaan dan keceriaan. Anchor kembali dipasang untuk memantapkan pemasangan anchor sebelumnya dengan meletakkan tangan kanan ibu didada sambil melakukan afirmasi bahwa mulai saat ini dan seterusnya setiap kali ibu meletakkan tangan kanan didada dan menarik nafas dalam, maka secara otomatis ibu akan berada ditempat dan kondisi bahagia yang dialami saat ini. Ibu diminta untuk mengulangi pemasangan anchor setiap hari pada setiap menjelang tidur selama 21 hari. Hal ini dapat bermanfaat untuk mengurangi kecemasan, serta rasa nyeri pada saat proses persalinan. Secara keseluruhan ibu hamil telah melakukan pengulangan pemasangan anchor setiap menjelang tidur dan kadang 
kadang diwaktu yang lain dan sudah melakukan komunikasi dengan bayi secara kontinue. Sebagian merasa lebih tenang dan lebih enjoy dalam menjalani kehamilan.

Yoga prenatal dilakukan untuk membuat ibu hamil mampu mempersiapkan fisik dan psikologis selama proses kehamilan, persalinan dan nifas. Pada pertemuan ketiga ini dipilih yoga dengan durasi yang lebih lama yaitu selama 30 menit yang terdiri dari unsolutation A, adhomukha svanasana, tadasana, trikonasana, virabhadrasana II, Utthita parsvakonasana, Ardha chandrasana, Prenatal Chaturangga, virksasana, diakhiri dengan rileksasi.

\section{Pertemuan keempat}

Kegiatan dilakukan dalam 3 sesi karena tempat di Polindes Socah yang tidak memungkinkan untuk menampung seluruh ibu hamil untuk kelas hypnoprenatal. Masing masing sesi terdiri dari 6 - 7 ibu hamil trimester 2 dan 3.

Pada pertemuan keempat ini diawali dengan penjelasan kembali tentang kelas hypnoprenatal, informed concent, pemeriksaan kehamilan dan pengatasan keluhan, hypnoprenatal dan pemasangan anchor, serta yoga prenatal.

Pemeriksaan kehamilan dilakukan untuk mendeteksi apakah dalam kehamilan ini terdapat kontraindikasi untuk melakukan hypnoprenatal maupun yoga antenatal. Dari keseluruhan ibu hamil didapatkan tidak terdapat kontraindikasi. Seluruh ibu hamil mengikuti proses hypnoprenatal dan yoga prenatal.

Pemasangan anchor dengan membimbing ibu berada dalam suatu tempat yang disukai dan memasuki kondisi penuh kebahagiaan dan keceriaan. Anchor kembali dipasang untuk memantapkan pemasangan anchor sebelumnya dengan meletakkan tangan kanan ibu didada sambil melakukan afirmasi bahwa mulai saat ini dan seterusnya setiap kali ibu meletakkan tangan kanan didada dan menarik nafas dalam, maka secara otomatis ibu akan berada ditempat dan kondisi bahagia yang dialami saat ini. Ibu diminta untuk mengulangi pemasangan anchor setiap hari pada setiap menjelang tidur selama 21 hari. Hal ini dapat bermanfaat untuk mengurangi kecemasan, serta rasa nyeri pada saat proses persalinan. Secara keseluruhan ibu hamil telah melakukan pengulangan pemasangan anchor setiap menjelang tidur dan kadang kadang diwaktu yang lain dan sudah melakukan komunikasi dengan bayi secara kontinue. Sebagian merasa lebih tenang dan lebih enjoy dalam menjalani kehamilan.

Yoga prenatal dilakukan untuk membuat ibu hamil mampu mempersiapkan fisik dan psikologis selama proses kehamilan, persalinan dan nifas. Pada pertemuan keempat ini dipilih yoga dengan durasi yang lebih lama yaitu selama 30 menit yang terdiri dari unsolutation A, 
adhomukha svanasana, tadasana, trikonasana, virabhadrasana II, Utthita parsvakonasana, Ardha chandrasana, Prenatal Chaturangga, virksasana, diakhiri dengan rileksasi.

\section{Pertemuan kelima}

Kegiatan dilakukan dalam 3 sesi karena tempat di Polindes Socah yang tidak memungkinkan untuk menampung seluruh ibu hamil untuk kelas hypnoprenatal. Masing masing sesi terdiri dari 6 - 7 ibu hamil trimester 2 dan 3.

Pada pertemuan kelima ini diawali dengan penjelasan kembali tentang kelas hypnoprenatal, informed concent pemeriksaan kehamilan dan pengatasan keluhan, hypnoprenatal dan pemasangan anchor, serta yoga prenatal.

Pemeriksaan kehamilan dilakukan untuk mendeteksi apakah dalam kehamilan ini terdapat kontraindikasi untuk melakukan hypnoprenatal maupun yoga antenatal. Dari keseluruhan ibu hamil didapatkan tidak terdapat kontraindikasi. Seluruh ibu hamil mengikuti proses hypnoprenatal dan yoga prenatal.

\section{Pemasangan anchor dengan} membimbing ibu berada dalam suatu tempat yang disukai dan memasuki kondisi penuh kebahagiaan dan keceriaan. Anchor kembali dipasang untuk memantapkan pemasangan anchor sebelumnya dengan meletakkan tangan kanan ibu didada sambil melakukan afirmasi bahwa mulai saat ini dan seterusnya setiap kali ibu meletakkan tangan kanan didada dan menarik nafas dalam, maka secara otomatis ibu akan berada ditempat dan kondisi bahagia yang dialami saat ini. Ibu diminta untuk mengulangi pemasangan anchor setiap hari pada setiap menjelang tidur selama 21 hari. Hal ini dapat bermanfaat untuk mengurangi kecemasan, serta rasa nyeri pada saat proses persalinan. Secara keseluruhan ibu hamil telah melakukan pengulangan pemasangan anchor setiap menjelang tidur dan kadang kadang diwaktu yang lain dan sudah melakukan komunikasi dengan bayi secara kontinue. Sebagian merasa lebih tenang dan lebih enjoy dalam menjalani kehamilan.

Yoga prenatal dilakukan untuk membuat ibu hamil mampu mempersiapkan fisik dan psikologis selama proses kehamilan, persalinan dan nifas. Pada pertemuan kelima ini dipilih yoga dengan durasi yang lebih lama yaitu selama 30 menit yang terdiri dari unsolutation A, adhomukha svanasana, tadasana, trikonasana, virabhadrasana II, Utthita parsvakonasana, Ardha chandrasana, Prenatal Chaturangga, virksasana, diakhiri dengan rileksasi.

1. Evaluasi proses dilaksanakan setiap kali pelaksanaan kegiatan hypnoprenatal. Secara keseluruhan ibu hamil trimester 2 dan 3 tidak terdapat kontraindikasi untuk dilakukan hypnoprenatal maupun yoga antenatal. 
Seluruh ibu hamil mengikuti kegiatan dengan kondisi yang santai, dan nyaman. Hasil rekapitulasi kuesioner pre dan post kelas hypnoprenatal didapatkan secara keseluruhan ibu dapat mengatasi kecemasan dan merasa lebih tenang dalam menjalani kehamilan, dan merasa lebih siap dalam menghadapi persalinan. secara keseluruhan ibu hamil menyatakan telah mengulang anchor yang dipasang setiap waktu.

\section{KESIMPULAN}

Berdasarkan kegiatan yang telah dilakukan dapat ditarik kesimpulan sebagai berikut:

1. Kegiatan kelas hypnoprenatal di Desa Keleyan wilayah kerja puskesmas Socah dilaksanakan dalam 5 kali pertemuan dan berjalan dengan baik.

2. Secara keseluruhan ibu hamil trimester 2 dan 3 tidak terdapat kontraindikasi untuk mendapatkan hypnoprenatal maupun yoga antenatal.

3. Ibu hamil yang mengikuti kelas hypnoprenatal menyatakan merasa lebih tenang dalam menjalani kehamilan, dan merasa lebih siap dalam menghadapi persalinan.

Berdasarkan simpulan diatas diharapkan semua bidan dapat memberikan asuhan antenatal secara holistik dengan menambahkan layanan hypnoprenatal agar ibu hamil dapat meningkatkan kemampuan untuk mengelola kondisi fisik dan psikisnya sendiri dalam menjalani kehamilan dan persalinan

\section{REFERENSI}

Sari, Ririn. Dwi, Ni Wayan, Gunawan, 2012, Hypnosis dalam mengurangi cemas dan nyeri antenatal, Jurnal Keperawatan, Vol 3 Nomor 2 Juli 2012 versi online

Cyna, Allan M. Dkk. 2006. Hypnosis antenatal training for childbirth : a randomiced controlled trial. BMC Pregnancy and childbirth, 2006 6:5 diakses melalui https://biomedcentral.com/14712393/6/5

Prawirohardjo, Wignyosastro, 2010. Ilmu Kebidanan, Jakarta, YBPS.

Sumarah. 2009. Perawatan Ibu Bersalin (Asuhan Kebidanan Pada Ibu Bersalin). Yogyakarta : Fitramaya

Susilowati Umi , 2017, Modul Pelatihan Basic Hypnotherapi, Jakarta, IBH, Jakarta

Susilowati Umi , 2017, Modul Pelatihan Hypnoprenatal, Jakarta, IBH,

Varney, Hellen, 2007, Buku Ajar Asuhan Kebidanan Edisi 4, Jakarta, EGC 